All this speculation, which you may take or leave, leads to one concrete recommendation, which you may judge on its own merits. This is that the political education of schoolchildren, which is a subject of much debate at the moment in the UK, would be brought to a fine focus and would serve the purposes outlined above, if it were to take as a project some technological issue such as the need for fast breeder reactors, or the wisdom of expanding the Windscale reprocessing plant. Not only would this constitute a political education, but it would also draw together in the schools those two elements-the humanist and the scientist-that have been driven too far apart. Each would have a great deal to learn from the other.

\title{
The nuclear debate is about values
}

\begin{abstract}
David Pearce, Professor of Political Economy, University of Aberdeen and Director of the Windscale Assessment and Review Project, argues that any future nuclear inquiry must deal effectively with the differing values adopted by the nuclear industry and its objectors. The industry must drop its haughty assumption that opposition to it is 'irrational'.
\end{abstract}

DesPITE the acclaim with which Justice Parker's Report on the Windscale Inquiry was greeted in pro-nuclear circles, by Peter Shore and by many outside observers, it has had one effect which can only serve to strengthen and polarise the nuclear debate even more. It is easy to see that the selective, admonishing and often haughty style of the report was a tactical misfortune for the nuclear industry. For the industry all too often presents an image of infallibility, of being in possession of the truth, and of technological mastery in a context where such claims must defy credibility.

To deny this image of infinite credibility is to be branded as 'irrational', motivated by some immature ignorance, or reflecting some political stance unrelated to nuclear power - a kind of convenient 'coathanger' on which to hang an ideology not shared by the nuclear camp. It is difficult to know how far the industry reflects on the dilemma they create for themselves through this kind of argument. For the image of infinite credibility is non-sustainable: it is possible and credible to query the industry's claims. Yet to admit of error, doubt and to the unknown is to admit to risks in a wholly expensive and vastly important area of public investment. And such admissions may themselves carry risk of alarm and of generating further support for the opposition. It is a dilemma the industry must solve for itself. If anyone doubts that mistakes are made, they need only consult the recent work of David Henderson and Duncan Burn on the AGR programme (See P. D. Henderson, 'Two British Errors: Their Probable Size and Some Possible Lessons', Oxford Economic Papers, July 1977, and D. Burn, Nuclear Power and the Energy Crisis, Macmillan/ Trade Policy Research Centre, London, 1978).

To be fair, many 'men of reason' characterise the pronuclear stance. They admit the risks and the unknown. They argue, legitimately perhaps, that the abandonment of nuclear power or even the failure to take on fast breeder options, entails an unacceptable sacrifice of material wealth since renewable energy cannot meet the demands of a growing economy, at least for the foreseeable future. Moreover, it is difficult to see why any sane mortal would perpetrate false claims so as to foist an unsafe industry on an unsuspecting public, unless, of course, the desire to be right and to toe the party line has overwhelmed that sanity.

A more sensible view is that those responsible for policy have made the value judgement that, given their belief that the risk is small compared to that embraced by other energy futures (witness the emerging environmental critique of the heavy use of coal), the benefits outweigh the costs. But if that is so, a strange feature can be observed. On the pronuclear side it is legitimate to argue that the values which are assumed to prevail in current society, acquisitive, material values, are also the values of the future which will inherit a nuclear power programme. They may be right. The oddity is that, having embraced these values, there is an overt wish not to debate the equally legitimate value system which declares that a growth society is undesirable and therefore not in need of the nuclear infrastructure to sustain it.

In short, opposition to nuclear power can, and often does, derive from values which differ to those assumed or embraced by the industry and those who implement policy. If that is so, that opposition is rational even if it may be shown to be unshared by society expressing its views through some democratic process. What is needed is a clearer statement of what the costs and benefits of different energy futures look like, a need that places onus on the opposition as well as on the industry. To go further, we then need institutions to debate and evaluate those alternatives so as to ensure that ultimate democratic bodies are appraised of those differences. If the industry is seen to have been 'right' all along, so be it. What is disconcerting is its presumption, never proven, that what it wants is what the public wants. And proof involves more, not less, public participation; more concern for a credible image rather than hysterical outbursts about the irrationality and political motivation of the opposition. If much the same can be said for elements of the opposition, it merely demonstrates the low level to which the debate can fall.

We have elsewhere stated a more detailed rationale for bringing debates on the value system into the nuclear controversy (see Windscale Assessment and Review Project, Interim Report, June 1978). It is also clear that no such debate will resolve conflict, any more than the local motorway inquiry leaves the opposing parties much closer to agreement. But that observation makes it all the more important to be sure that the decisions are correct and efficient and are ones for which there is public accountability (who, for example, is accountable for Concorde, or the AGR programme?). There is no escape from the logic that, if the case for fast breeders or reprocessing plants or whatever, implicitly embraces values, then it is proper to afford legitimacy to an opposition which happens to embrace a different value system. This logic was evidently missed by Justice Parker as his report so clearly demonstrates when it discusses the alternative views he was presented with. That section of the report (see The Windscale Inquiry: Report, Vol. 1, 1978, Sections of Ch.8) is characterised by a perplexity and confusion which he was obviously happy to retreat from, to return to the technical issues which, science demands, must be provable one way or the other.

Failure to modify institutions to accommodate the views outlined here, and failure of the nuclear industry to change its image of self-righteousness are recipes for a different, and undesirable, nuclear controversy-one of conflict and not debate. To some at least, there is a very high cost to be attached to such a future. The inquiry over CFR 1 , the first commercial fast reactor, will be one testing ground. Let us hope it occurs and is accompanied by a wider debate linked to better public information and proper political concern. $\square$ 